\title{
Characteristic expression pattern of oxidative stress in livers with cryptogenic hepatocellular carcinoma
}

\author{
NOBUYOSHI FUKUSHIMA ${ }^{1,5}$, RYOKO KUROMATSU ${ }^{1}$, JUN AKIBA ${ }^{2}$, EIJI ANDO $^{1}$, AKIO TAKATA ${ }^{1}$, \\ SHUJI SUMIE $^{1}$, MASAHITO NAKANO ${ }^{1}$, TORU NAKAMURA ${ }^{1}$, AKIHIKO KAWAHARA ${ }^{4}$, \\ TAKUJI TORIMURA ${ }^{1}$, OSAMU NAKASHIMA ${ }^{2}$, KOJI OKUDA $^{3}$, HIROHISA YANO $^{2}$, \\ MASAYOSHI KAGE ${ }^{4}$, MASAMICHI KOJIRO ${ }^{2}$ and MICHIO SATA ${ }^{1}$ \\ ${ }^{1}$ Division of Gastroenterology, Department of Medicine, and Departments of ${ }^{2}$ Pathology and ${ }^{3}$ Surgery, \\ Kurume University School of Medicine; ${ }^{4}$ Department of Diagnostic Pathology, Kurume University Hospital, \\ Kurume 830-0011; ${ }^{5}$ Department of Gastroenterology, Clinical Research Institute, \\ National Hospital Organization, Kyushu Medical Center, Fukuoka 810-8563, Japan
}

Received May 31, 2010; Accepted July 15, 2010

DOI: $10.3892 / \mathrm{etm} .2010 .132$

\begin{abstract}
The mechanism responsible for the development of hepatocellular carcinoma (HCC) in the setting of oxidative stress has yet to be clearly defined. We studied the role of oxidative stress in hepatocarcinogenesis in subjects without underlying chronic viral hepatitis. The subjects were 24 patients negative for serum hepatitis B surface antigen and hepatitis $\mathrm{C}$ antibody tests, who underwent hepatic resection for HCC (Group N). Subjects were excluded if diagnosed with liver disease predisposing to HCC. Immunohistochemical staining for oxidative stress-related markers was performed on non-cancerous liver regions. Resected liver tissues adjacent to HCC from 24 patients with chronic hepatitis B (Group B) and 21 patients with chronic hepatitis $\mathrm{C}$ (Group $\mathrm{C}$ ) were also examined. The percentage of 8-hydroxydeoxyguanosine-positive hepatocytes in Group $\mathrm{N}$ was significantly lower than that in Group B and that in the combined population of Groups B and C. The percentage of the area positive for 4-hydroxynonenal in Group $\mathrm{N}$ was significantly higher than that in Groups B or C. Meanwhile, the percentage of the area positive for manganese superoxide dismutase in Group N was not different from that in Groups $\mathrm{B}$ and $\mathrm{C}$. In conclusion, the mechanism of hepatocarcinogenesis through oxidative stress for patients without known liver disease predisposing to HCC may differ from that for patients with chronic viral hepatitis.
\end{abstract}

Correspondence to: Dr Nobuyoshi Fukushima, Division of Gastroenterology, Department of Medicine, Kurume University School of Medicine, 67 Asahi-machi, Kurume, Fukuoka 830-0011, Japan

E-mail: kingsno1@med.kurume-u.ac.jp

Key words: hepatocarcinogenesis, hepatoma, oxidative stress

\section{Introduction}

Hepatocellular carcinoma (HCC) is one of the most common types of cancers worldwide, particularly in Southeast Asia (1). Japan has one of the highest incidence rates of HCC among developed countries $(2,3)$. Worldwide and also in Japan, HCC is mainly caused by chronic hepatitis B virus (HBV) and hepatitis C virus (HCV) infection $(4,5)$. Nearly $90 \%$ of patients with HCC in Japan are chronically infected with HBV or HCV. Meanwhile, other patients with HCC in Japan have no confirmed chronic viral hepatitis, and the percentage of these patients is reportedly much higher in Western countries (6-8). Lately, the incidence of HCC without an underlying hepatitis virus infection is increasing $(9,10)$. HCC cases without chronic viral hepatitis include patients who suffer from other chronic liver diseases predisposing to $\mathrm{HCC}$, such as alcoholic liver disease (11), hemochromatosis (12), Budd-Chiari syndrome (13) and non-alcoholic steatohepatitis (NASH) (14). In addition, there is a subpopulation of patients with HCC that develops from normal liver or liver tissue damaged from an unknown cause at a constant rate.

Many recent reports suggest a close correlation of oxidative stress and the carcinogenicity of HCC. Reactive oxygen species are known to damage DNA and membranes, induce nucleotide mutation and apoptosis, and are thought to induce carcinoma (15). Oxidative stress is likely to be a key component in the induction of HCC.

8-Hydroxydeoxyguanosine $(8-\mathrm{OHdG})$ is a DNA basemodified product generated by reactive oxygen species and is a mutation prone to induce a G-C to T-A transversion during DNA replication (16). Previous studies have demonstrated that 8 -OHdG is implicated in carcinogenesis $(17,18)$ and hepatocarcinogenesis (19). 8-OHdG is induced during liver DNA damage (19) and expressed in livers with chronic hepatitis C (CH-C) (20) and chronic hepatitis B (CH-B) (21). 8-OHdG, a good marker of oxidative DNA damage, is thought to be involved in hepatocarcinogenesis in the setting of chronic viral hepatitis. 
Free radical-mediated damage to cellular membranes results in lipid peroxidation and generates a variety of DNA-reactive aldehydes, including 4-hydroxynonenal (4-HNE). 4-HNE interacts with proteins or DNA, yielding etheno (c)-modified DNA bases (22), and was reported to form DNA adducts in the human p53 gene at a unique mutational hot spot in HCC (23).

Superoxide dismutase (SOD) is a metalloenzyme and catalyzes the dismutation of superoxide anions into molecular oxygen and hydrogen peroxide. Thus, SOD plays an important role in defending cells against oxygen radical toxicity. Hepatocytes contain abundant mitochondria, and reactive oxygen species in hepatocytes are mainly generated in the mitochondria. Manganese SOD (MnSOD) is induced in the mitochondria by oxidative stress as well as by various stimuli, such as viral infections $(24,25)$. Therefore, MnSOD is thought to be a reliable marker of oxidative stress in hepatocytes.

In the present study, the expression levels of $8-\mathrm{OHdG}$, 4-HNE and MnSOD were measured in non-tumor liver tissue of HCC patients without diagnosed disease predisposing to HCC, and these indices were compared to those of HCC patients with $\mathrm{CH}-\mathrm{B}$ or $\mathrm{CH}-\mathrm{C}$. From these results, we propose the existence of different mechanisms of carcinogenesis through oxidative stress between normal livers or livers damaged by unknown etiologies and livers with chronic viral hepatitis.

\section{Materials and methods}

Patients. Resected HCC and non-tumor liver tissues adjacent to $\mathrm{HCC}$ were obtained from 24 patients negative for anti-HCV antibodies (HCV-Ab) and hepatitis B surface antigen (HBsAg) in serum (Group N). Patients diagnosed with chronic liver diseases, such as alcoholic liver disease and NASH, were excluded from Group N. In Group N, 11 patients were positive for the antibody to hepatitis B core antigen ( $\mathrm{HBcAb})$ in serum, 11 were negative and 2 were unknown. Tissue samples were also obtained from 21 patients positive for $\mathrm{HCV}-\mathrm{Ab}$, negative for $\mathrm{HBsAg}$ and $\mathrm{HBcAb}$ (Group C), and 24 patients negative for HCV-Ab and positive for HBsAg (Group B). Non-tumor liver tissues were also obtained from 3 patients with metastatic hepatic tumors (colon, gastric and maxillary sinus cancer) and negative for HCV-Ab and HBsAg in serum. All patients, including 3 controls, underwent partial hepatectomy at the Department of Surgery, Kurume University School of Medicine, from January 1995 to September 2004. All patients fulfilled the following conditions. i) Primary tumors, except for 3 metastatic tumors; ii) initial therapy for hepatic tumors; iii) patients who abused alcohol (daily intake $>60 \mathrm{~g}$ of ethanol for male, $>40 \mathrm{~g}$ for female) were excluded; iv) patients with co-existing liver disease diagnosed by clinical and histological examination, such as alcoholic liver disease, NASH, hemochromatosis, Wilson disease, autoimmune hepatitis, primary biliary cirrhosis, Budd-Chiari syndrome and Schistosomiasis japonica, were excluded. Surgically resected liver tissues were fixed in formalin and embedded in paraffin, and serial sections (4- $\mu \mathrm{m}$ thick) were prepared. Informed consent was obtained from each patient, and the study was approved by the Ethics Committee of Kurume University. The study was carried out according to the ethical guidelines of the 1975 Declaration of Helsinki.
Clinical data and histological assessment. Baseline data included the following characteristics: age, gender, diagnosis of diabetes mellitus (DM), body mass index (BMI), serum levels of aspartate aminotransferase (AST), alanine aspartate aminotransferase (ALT), total bilirubin, albumin and $\alpha$-fetoprotein, prothrombin time, platelet count and indocyanine green retention (ICG R15). BMI was calculated as weight in kilograms/height in meters squared. Hepatic function before the resection was evaluated using the Child-Pugh classification (26) and the liver damage grade of the Liver Cancer Study Group of Japan (27). Histopathological features of tumors at the time of surgery, including maximal tumor diameter, tumor number and tumor differentiation (28), were also assessed. Tumor staging of HCC was determined using the tumor node metastasis (TMN) classification (29).

H\&E staining was performed for the histological diagnosis. Assessment of liver fibrosis and inflammation was made according to the classification of Desmet et al (30). Hepatic steatosis was also graded according to Brunt et al (31). In short, steatosis observed in up to $33,33-66$ and $>66 \%$ of the liver histology was determined as grade 1,2 and 3, respectively. Hepatic steatosis, if not observed, was graded as grade 0 . The histological quantification of hepatic iron was carried out according to Deugnier et al (32) using liver samples stained with Berlin blue instead of Perl's Prussian blue. The total iron score (TIS, 0-60) calculated by this scoring system was shown to correlate highly with the biochemical hepatic iron index and hepatic iron concentration as measured by atomic absorption spectrophotometry in patients with chronic liver disease.

Immunohistochemistry. Each paraffin section was first deparaffinized. For immunohistochemical staining of $8-\mathrm{OHdG}$, sections were heated in $10 \mathrm{mM}$ sodium citrate buffer $(\mathrm{pH}$ 6.0) at $121^{\circ} \mathrm{C}$ for $10 \mathrm{~min}$ in an autoclave and then treated with $0.3 \%$ hydrogen peroxide in methanol for $15 \mathrm{~min}$. After the sections were washed three times with phosphate-buffered saline (PBS), they were incubated with Protein Block (Dako Japan Inc., Kyoto, Japan) for $1 \mathrm{~h}$ at room temperature and sequentially reacted with mouse monoclonal antibody against 8-OHdG (1:50 dilution; Japan Institute for the Control of Aging, Shizuoka, Japan) overnight at $4^{\circ} \mathrm{C}$. After the sections were rinsed in PBS three times, they were incubated with a biotinylated secondary antibody conjugated with avidinbiotin-horseradish peroxidase (Dako Japan Inc.) and reacted with 3,3-diaminobenzidine (DAB), and subsequently the sections were counterstained with Mayer's hematoxylin for $1 \mathrm{~min}$. For immunohistochemical staining of 4-HNE, sections were heated in $10 \mathrm{mM}$ sodium citrate buffer $(\mathrm{pH} 6.0)$ at $100^{\circ} \mathrm{C}$ for $5 \mathrm{~min}$ in a microwave and reacted with mouse monoclonal antibody against 4-HNE (1:160 dilution; Japan Institute for the Control of Aging) overnight at $4^{\circ} \mathrm{C}$. For immunohistochemical staining of MnSOD, sections were reacted with rabbit polyclonal antibody against MnSOD (1:1,600 dilution; Abcam Inc., Cambridge, MA, USA) overnight at $4^{\circ} \mathrm{C}$. For the detection of the staining of 4-HNE and MnSOD, the ChemMate Envision method (Dako Japan Inc.) was used with DAB as the chromagen.

Hepatocytes that stained positively for $8-\mathrm{OHdG}$ were counted in at least five different random fields at a $\mathrm{x} 400$ magnification, and the number of positive cells per 1,000 
Table I. Comparison of clinical characteristics among the groups based on viral markers.

\begin{tabular}{|c|c|c|c|c|c|c|}
\hline & \multirow[t]{2}{*}{ Group $\mathrm{N}^{\mathrm{a}}$} & \multirow[t]{2}{*}{ Group Ba } & \multirow[t]{2}{*}{ Group $C^{a}$} & \multicolumn{3}{|c|}{ p-value ${ }^{b}$} \\
\hline & & & & $\mathrm{N}-\mathrm{B}$ & $\mathrm{N}-\mathrm{C}$ & $\mathrm{B}-\mathrm{C}$ \\
\hline Age $(\text { years })^{c}$ & $67.1 \pm 10.1$ & $54.9 \pm 11.6$ & $65.2 \pm 8.2$ & $<0.001$ & NS & 0.003 \\
\hline Gender (male/female) & $20 / 4$ & $16 / 8$ & $16 / 5$ & NS & NS & NS \\
\hline Body mass index ${ }^{c}$ & $22.6 \pm 3.30$ & $22.9 \pm 3.0$ & $23.4 \pm 2.6$ & NS & NS & NS \\
\hline $\mathrm{DM}(-/+)$ & $12 / 8$ & $21 / 0$ & $18 / 1$ & 0.001 & 0.020 & NS \\
\hline $\operatorname{AST}(\mathrm{IU} / \mathrm{l})^{\mathrm{c}}$ & $41.5 \pm 21.2$ & $78.8 \pm 149.1$ & $55.9 \pm 32.8$ & NS & NS & NS \\
\hline $\operatorname{ALT}(\mathrm{IU} / \mathrm{l})^{\mathrm{c}}$ & $33.6 \pm 49.6$ & $46.6 \pm 33.0$ & $64.5 \pm 46.5$ & NS & 0.001 & NS \\
\hline Total bilirubin $(\mathrm{mg} / \mathrm{dl})^{\mathrm{c}}$ & $0.85 \pm 0.41$ & $1.15 \pm 0.55$ & $0.88 \pm 0.29$ & 0.041 & NS & NS \\
\hline Albumin $(\mathrm{g} / \mathrm{dl})^{\mathrm{c}}$ & $3.8 \pm 0.3$ & $3.9 \pm 0.5$ & $3.8 \pm 0.4$ & NS & NS & NS \\
\hline Prothrombin time $(\%)^{\mathrm{c}}$ & $93.4 \pm 15.8$ & $86.6 \pm 11.7$ & $89.1 \pm 10.3$ & NS & NS & NS \\
\hline $\operatorname{ICG}(15)(\%)^{\mathrm{c}}$ & $14.0 \pm 6.20$ & $11.8 \pm 9.8$ & $20.0 \pm 12.1$ & NS & NS & 0.010 \\
\hline Platelet $\left(\times 10^{4} / \mathrm{ml}\right)^{\mathrm{c}}$ & $19.9 \pm 10.3$ & $15.5 \pm 5.8$ & $12.7 \pm 4.40$ & NS & 0.003 & NS \\
\hline$\alpha$-fetoprotein $(\mathrm{ng} / \mathrm{ml})^{\mathrm{d}}$ & $\begin{array}{c}58.3 \\
(1.5-12,850)\end{array}$ & $\begin{array}{c}36.2 \\
(2.4-559,791)\end{array}$ & $\begin{array}{c}33.9 \\
(3.0-42,568)\end{array}$ & NS & NS & NS \\
\hline Liver damage (A/B,C) & $18 / 4$ & $16 / 7$ & $16 / 4$ & NS & NS & NS \\
\hline Child-Pugh (score 5/6) & $15 / 9$ & $16 / 7$ & $17 / 4$ & NS & NS & NS \\
\hline Tumor size $(\mathrm{mm})^{\mathrm{c}, \mathrm{e}}$ & $69.8 \pm 49.6$ & $61.0 \pm 43.0$ & $34.0 \pm 19.9$ & NS & 0.001 & 0.009 \\
\hline No. of tumors (single/multiple) & $13 / 11$ & $18 / 6$ & $13 / 8$ & NS & NS & NS \\
\hline Tumor stage (I,II/III,IV) & $7 / 17$ & $10 / 14$ & $9 / 10$ & NS & NS & NS \\
\hline
\end{tabular}

Only patients with available data for all of the characteristics listed above were included. ${ }^{\mathrm{a} G r o u p ~ N, 24}$ patients with HCC negative for HCVAb

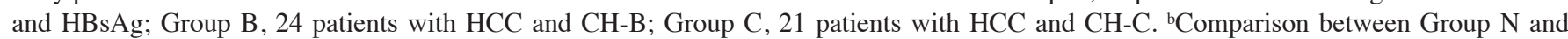
Group B (N-B), between Group N and Group C (N-C) and between Group B and Group C (B-C). p-values were calculated with the Chi-square test, Fisher's exact probability test or Mann-Whitney U test. ${ }^{c}$ Means \pm standard deviation. ${ }^{d}$ Median (range). ${ }^{e}$ Maximal tumor diameter. DM, type 2 diabetes mellitus; AST, aspartate aminotransferase; ALT, alanine aspartate aminotransferase; ICG(15), indocyanine green retention; NS, not significant. Values in bold indicate statistical significance.

hepatocytes was calculated. Quantitation of 4-HNE-protein adducts and MnSOD was performed using image analysis software (WinROOF; Mitani Corp., Fukui, Japan) by evaluating five different random fields (magnification $\mathrm{x} 400$ ) for positively stained hepatocytes and expressed as a percentage of the total area. Stained inflammatory, Kupffer and bile duct cells were eliminated before quantitation for 4-HNE-protein adducts and MnSOD using image analysis software.

Statistics. Statistical analysis was performed using SPSS 12.0J (SPSS Inc., Chicago, IL, USA). The Chi-square test or Fisher's exact probability test was used to compare categorical data. Differences between two groups were evaluated using the Mann-Whitney U test. A relationship between different continuous variables was investigated by linear regression analysis. A p-value $<0.05$ was considered statistically significant.

\section{Results}

Clinical characteristics. Comparison of the clinical characteristics among the three groups is summarized in Table I. Patients in Group B were significantly younger than patients in Group C ( $\mathrm{p}=0.003)$ and Group N $(\mathrm{p}<0.001)$. In Group N, 8 patients were diagnosed with $\mathrm{DM}$ and 12 were not, and 1 patient was unknown. The proportion of patients with DM in Group $\mathrm{N}$ was significantly higher than that in Group B $(p=0.001)$ or Group C $(p=0.020)$. Serum levels of ALT in Group $\mathrm{N}$ were significantly lower than those in Group $\mathrm{C}$ $(p=0.001)$. Total bilirubin in Group $\mathrm{N}$ was significantly lower than that in Group B $(\mathrm{p}=0.041)$, and platelet counts in Group $\mathrm{N}$ were significantly higher than those in Group $\mathrm{C}$ $(\mathrm{p}=0.003)$. Tumor size was significantly smaller in Group $\mathrm{C}$ than in Groups B or $\mathrm{N}(\mathrm{p}=0.009$ and 0.001 , respectively). Gender, BMI, serum levels of AST, albumin, $\alpha$-fetoprotein, prothrombin time, ICG R15 and number of tumors in Group N were not different from those in the other two groups. There were no significant differences in Child-Pugh classification, liver damage grade or tumor staging among the three groups.

Histological features. Table II shows the histological features of the study population. There were 4 patients in Group $\mathrm{N}$ with grade 0 for histological hepatic inflammatory activity, as well as stage 0 for hepatic fibrosis. When the patients with grades of hepatic inflammation were divided into A0-1 and A2-3, the grades of histological inflammatory activity in Group $\mathrm{C}$ were significantly higher than those in Group B $(\mathrm{p}=0.006)$ and Group N $(\mathrm{p}<0.001)$. When the stages of hepatic fibrosis were divided into F0-2 and F3-4, the histological fibrotic stages in Group $\mathrm{N}$ were significantly lower than those in Group B $(p=0.008)$ and Group $C(p=0.029)$. There was no patient with hepatic steatosis assessed as grade 3 in this study and, when divided into grade 0 and grade $1-2$, there were no significant 
Table II. Comparison of the histological characteristics of background liver tissue among the groups based on viral markers.

\begin{tabular}{lcccccc}
\hline & Group N & Group B & Group C & & \multicolumn{2}{c}{ p-value } \\
\cline { 5 - 7 } & & & & N-B & N-C & B-C \\
\hline Grading A0/1/2/3 & $5 / 19 / 0 / 0$ & $1 / 19 / 4 / 0$ & $0 / 9 / 12 / 0$ & NS & $<\mathbf{0 . 0 0 1}$ & $\mathbf{0 . 0 0 6}$ \\
Staging F0/1/2/3/4 & $8 / 9 / 5 / 1 / 1$ & $1 / 11 / 1 / 6 / 5$ & $0 / 6 / 7 / 5 / 3$ & $\mathbf{0 . 0 0 8}$ & $\mathbf{0 . 0 2 9}$ & NS \\
Fatty deposit grade 0/1/2/3 & $8 / 16 / 0 / 0$ & $9 / 14 / 1 / 0$ & $3 / 17 / 1 / 0$ & NS & NS & NS \\
Iron deposit (total iron score) & $11.3 \pm 7.7$ & $10.2 \pm 7.0$ & $7.7 \pm 7.1$ & NS & NS & NS \\
\hline
\end{tabular}

Each group was compared after partitioning to A0-1 and A2-3 for hepatic inflammation (grading), to F0-2 and F3-4 for hepatic fibrosis (staging) and to grade 0 and grade 1-2 for hepatic steatosis. ${ }^{a}$ Comparison between Group N and Group B (N-B), between Group N and Group C (N-C) and between Group B and Group C (B-C). p-values were calculated with the Chi-square test, Fisher's exact probability test or Mann-Whitney U test. ${ }^{b}$ The histological quantification of hepatic iron was carried out according to Deugnier et al (32) and was represented as the mean \pm standard deviation. NS, not significant. Values in bold indicate statistical significance.
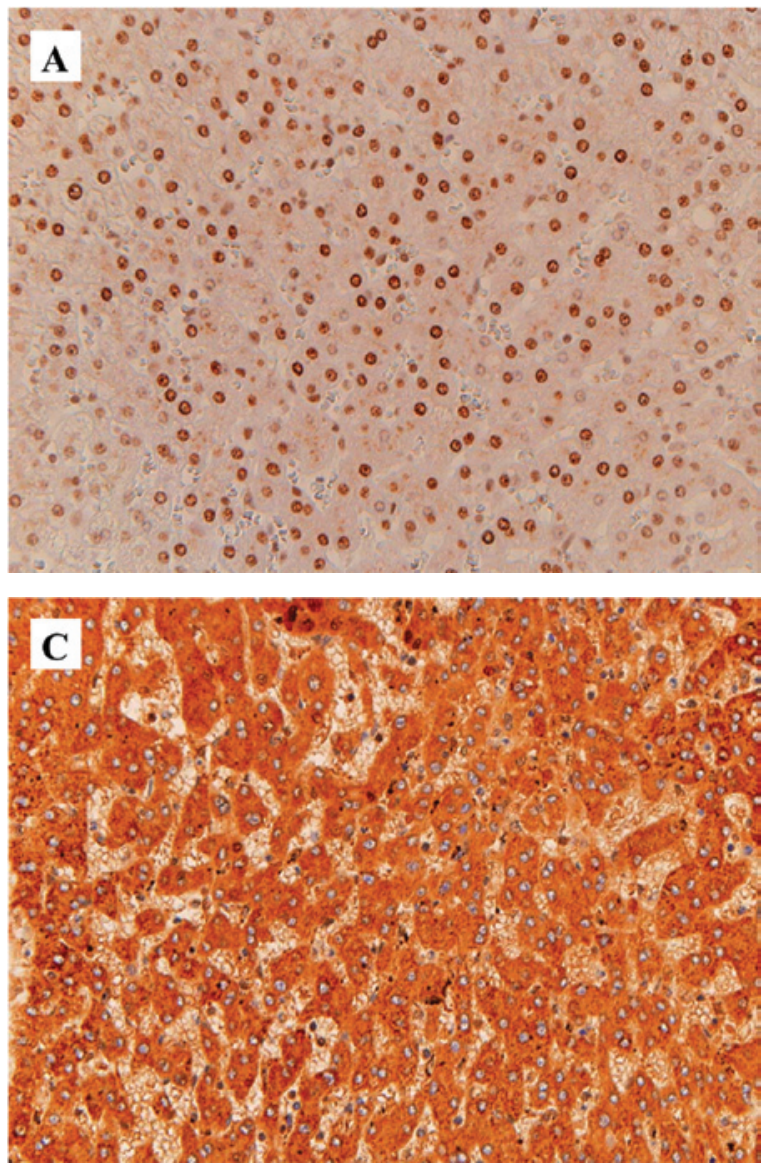

differences between groups. There was also no difference in the TIS score reflecting hepatic iron deposition between each group.

Immunohistochemical staining. Fig. 1 is a representative image of staining for 8-OHdG (A), 4-HNE (B) and Mn-SOD (C) in the non-cancerous liver tissues. Table III and Fig. 2 show the results of the immunohistochemical analysis for $8-\mathrm{OHdG}$, 4-HNE and MnSOD. Immunohistochemical staining revealed that the number of $8-\mathrm{OHdG}$-positive hepatocytes per 1,000 cells in Group N (median 1.4, range 0-235.6) was significantly lower than that in Group B (median 15.2, range 0-403.1)

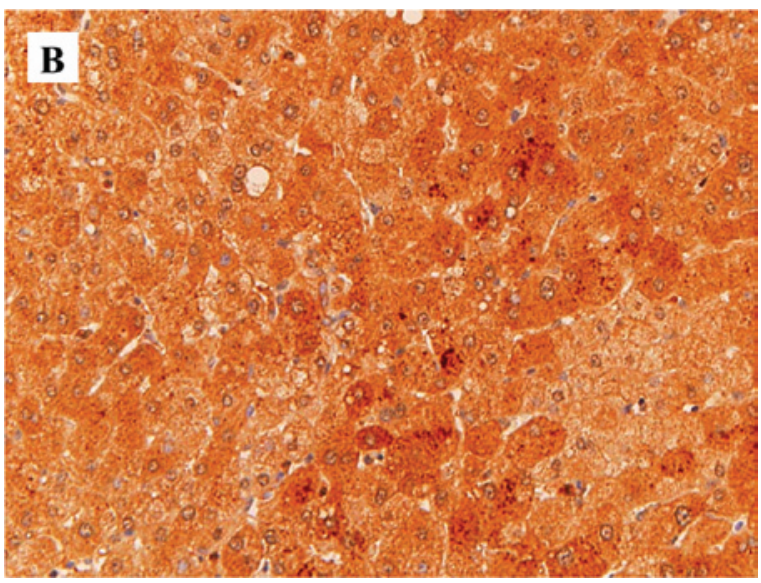

Figure 1. Representative image of immunohistochemical staining in noncancerous liver tissue from patients. (A) Staining for $8-\mathrm{OHdG}$ in a patient with HCC negative for HCVAb and HBsAg (Group N). Many 8-OHdG-positive cells with a brown-stained nucleus were present in the section. Apart from hepatocytes, 8-OHdG-positive cells, such as Kupffer and infiltrative lymphocyte cells, were eliminated from the counting. Staining for 4-HNE (B) and Mn-SOD (C) in a patient with HCC negative for HCVAb and positive for HBsAg (Group B). Many 4-HNE- and Mn-SOD-positive cells were present in the section. Positive cells for both, except hepatocytes, were eliminated before quantitation.

$(\mathrm{p}=0.014)$ and that in the combined Groups B and C (median 5.75 , range $0-403.1)(\mathrm{p}=0.016)$. The number of $8-\mathrm{OHdG}-$ positive cells in the three controls with metastatic hepatic tumors (0, 0 and 26.1) was not significantly different from that in the other three groups. Meanwhile, the ratio of 4-HNE-positive cells to total area in Group N (median 1.96, range 0.06-26.46) was significantly higher than that in Group B (median 0.62, range 0.07-4.68) $(\mathrm{p}<0.001)$ and that in Group $\mathrm{C}$ (median 0.36, range 0.01-8.50) $(\mathrm{p}<0.001)$. Additionally, the ratio of $4-\mathrm{HNE}$ positive cells to total area in the three controls $(0.6,1.0$ and 2.2) was not significantly different from that in the other three groups. The ratio of MnSOD-positive cells to total area in 
$\mathbf{A}$

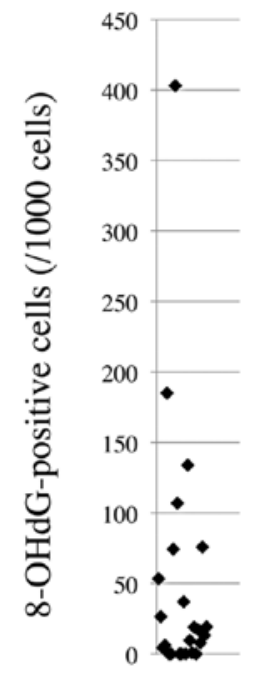

Group B

B

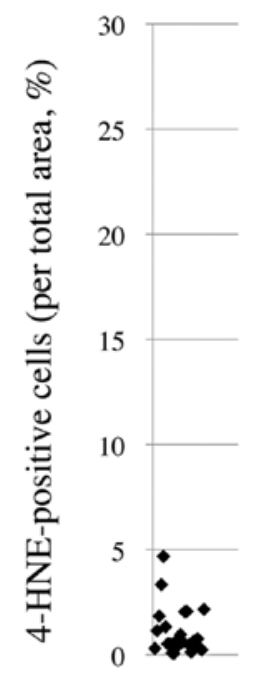

Group B

C

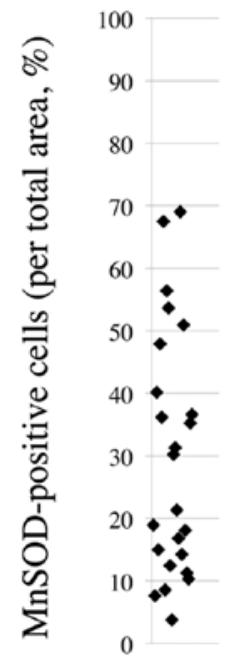

Group B

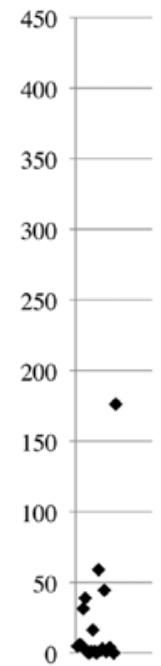

Group C

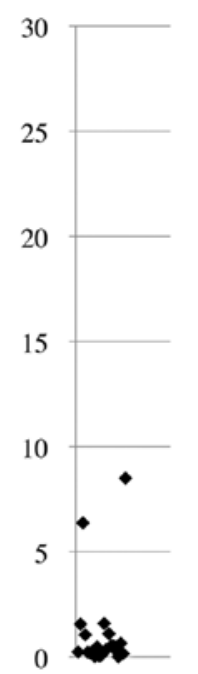

Group C

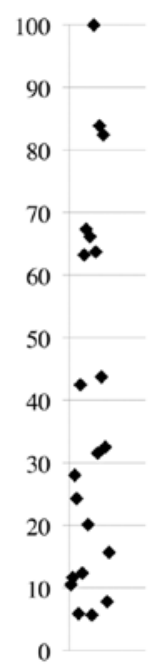

Group C

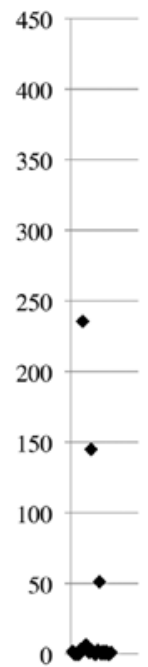

Group N

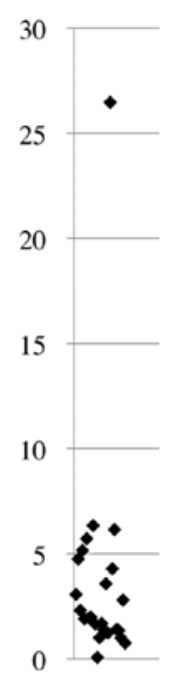

Group N

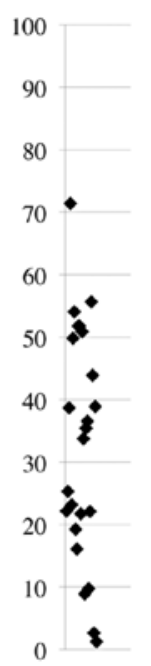

Group N

Figure 2. Values for the ratios of the number of 8-OHdG-positive hepatocytes per 1,000 cells (A) and 4-HNE- (B) and Mn-SOD-positive cells (C) to the total area for each case in the three groups. Group N represents 24 patients with HCC negative for HCVAb and HBsAg, Group B represents 24 patients with $\mathrm{HCC}$ negative for $\mathrm{HCVAb}$ and positive for $\mathrm{HBsAg}$, and Group C represents 21 patients with $\mathrm{HCC}$ positive for $\mathrm{HCVAb}$, negative for $\mathrm{HBsAg}$ and antibody to hepatitis B core antigen in the serum.

Group N (median 34.6; range 1.3-71.4) was not different from that in Group B (median 25.8, range 3.8-69.0) or Group C (median 31.5, range 9.0-54.6). The ratio of MnSOD-positive cells to total area in the three controls $(26.2,31.0$ and 44.5) was not significantly different from that in the other groups. There was no significant difference in $8-\mathrm{OHdG}, 4-\mathrm{HNE}$ and MnSOD between the patients positive and negative for $\mathrm{HBcAb}$ in Group N.

For the total patients with $\mathrm{HCC}$, including Groups B, C and $\mathrm{N}$, the number of 8 -OHdG-positive cells, the ratio of 4-HNE-positive cells and the ratio of MnSOD-positive cells did not correlate with each other. The number of 8-OHdGpositive cells and the ratio of MnSOD-positive cells were not correlated with hepatic inflammatory activity grade, fibrotic stage, grade of steatosis, TIS score reflecting iron deposition, BMI or age. The percentage of 4-HNE-positive cells showed a weak negative correlation with inflammatory activity grade $(\mathrm{p}=0.006, \mathrm{r}=-0.329)$, fibrotic stage $(\mathrm{p}=0.010, \mathrm{r}=-0.308)$ and grade of fatty deposition $(\mathrm{p}=0.025, \mathrm{r}=-0.270)$.

\section{Discussion}

Previous reports have noted the high expression of $8-\mathrm{OHdG}$ in the livers of chronic viral hepatitis patients $(20,21)$, and our results are consistent with these reports. Recent studies have shown that high expression of 8-OHdG in livers with $\mathrm{CH}-\mathrm{C}$ predicted the development of primary $\mathrm{HCC}(33,34)$ and also postoperative recurrence $(35,36)$, suggesting the association of 8-OHdG and carcinogenesis in livers with $\mathrm{CH}-\mathrm{C}$. However, the expression levels of $8-\mathrm{OHdG}$ in the livers of Group $\mathrm{N}$ were low, suggesting that abundant expression of $8-\mathrm{OHdG}$ is not essential for developing HCC. Recent studies have demonstrated that $8-\mathrm{OHdG}$ is correlated with hepatic inflammation and fibrosis in non-cancerous liver tissue of patients with $\mathrm{HCV}$ and HCC (33-35). The lower expression of 8-OHdG in Group N may reflect a lower grade of inflammation or a lower stage of fibrosis in the livers of these patients compared to the livers of patients with $\mathrm{CH}-\mathrm{B}$ and $\mathrm{CH}-\mathrm{C}$.

The expression level of 4-HNE in livers of patients with hepatitis is controversial. 4-HNE was reported to be a good biomarker for predicting disease-free survival in patients with $\mathrm{HCC}$ and $\mathrm{CH}-\mathrm{C}$; however, a weaker association with disease outcome when compared to 8-OHdG was noted (36). Maki et al reported high expression of 4-HNE in livers with $\mathrm{CH}-\mathrm{C}$ and $\mathrm{HCC}$ compared to controls (36), while in another study, 4-HNE protein adducts were detected in only a few hepatocytes in livers with $\mathrm{CH}-\mathrm{C}$ (37). The expression level of 4-HNE protein adducts in livers with $\mathrm{CH}-\mathrm{B}$ was found to be lower than that in livers with CH-C (38). In this study, the expression levels of 4-HNE in the livers of Group N subjects were higher than those in Groups B and C. Although the number of controls was quite small, the average of the expression levels of 4-HNE in the controls $(0.61,1.03$ and 2.20) was 1.28 , and the expression levels of 4-HNE of 19 cases out of 24 in Group $\mathrm{N}$ were higher than the average level in the controls. These results suggest the possibility that 4-HNE plays a crucial role in hepatocarcinogenesis in normal livers or cryptogenic liver damage. Meanwhile, Coleman et al showed that 4-HNE is an agonist of nuclear receptor peroxisome proliferator-activated receptors (PPARs) and 
Table III. Comparison of the expression levels for oxidative stress markers on liver tissue adjacent to hepatocellular carcinoma among the groups based on viral markers.

\begin{tabular}{lcrrrrr}
\hline & Group N & Group B & Group C & & \multicolumn{3}{c}{ p-value $^{\mathrm{a}}$} \\
\cline { 5 - 7 } & & & & N-B & N-C & B-C \\
\hline 8-OHdG & $1.40(0-235.60)$ & $15.20(0-403.10)$ & $2.99(0-176.19)$ & $\mathbf{0 . 0 1 4}$ & 0.097 & 0.217 \\
4-HNE & $1.96(0.06-26.46)$ & $0.62(0.07-4.68)$ & $0.36(0.01-8.50)$ & $<\mathbf{0 . 0 0 1}$ & $<\mathbf{0 . 0 0 1}$ & 0.139 \\
MnSOD & $34.60(1.3-71.40)$ & $25.80(3.8-69.0)$ & $31.50(5.7-100.0)$ & 0.433 & 0.733 & 0.453 \\
\hline
\end{tabular}

Data are shown as the median value (range). ${ }^{a}$ Comparison between Group N and Group B (N-B), between Group N and Group C (N-C) and between Group B and Group C (B-C). p-values were calculated with the Mann-Whitney U test. NS, not significant. Values in bold indicate statistical significance.

suggested that 4-HNE decreases oxidative stress-associated liver damage through the activation of PPARs (39). Lower expression of 4-HNE in Groups B and C compared to Group $\mathrm{N}$ may suggest the suppression of PPARs, and subsequently less attenuation of oxidative damage in the livers of chronic viral hepatitis subjects. If so, oxidative stress may be involved to a lesser extent in hepatocarcinogenesis in normal livers or livers damaged by unknown etiologies. A weak negative correlation of the expression levels of 4-HNE with the grade of hepatic inflammatory activity, fibrotic stage and grade of fatty deposition in our study might reflect the role of 4-HNE against liver damage.

Several studies have shown that chronic hepatitis virus infection may increase MnSOD expression and activity as an adaptive response to increased superoxide ions $(25,40)$, and the elevation of serum levels and histological expression for MnSOD was shown in patients with HCC (41-43). Meanwhile, the association of gene polymorphisms in MnSOD with high MnSOD activity and an increased risk for HCC has been reported $(44,45)$. These findings suggest that MnSOD is not only an enzyme induced as an adaptive response to oxidative stress, but also a key factor in the acceleration of tumor growth through anti-apoptotic factors (43). In this study, the expression levels of MnSOD in all three groups and controls were not significantly different, which means that a specific role of MnSOD in carcinogenesis or protection from oxidative stress in normal livers or cryptogenic liver damage compared to livers with chronic viral hepatitis was not found.

Varying expression levels of oxidative markers have been reported in liver tissue in conditions known to cause $\mathrm{HCC}$, other than $\mathrm{CH}-\mathrm{B}$ and $\mathrm{CH}-\mathrm{C}$. Several studies have found frequently increased expression of 8-OHdG and strong staining of 4-HNE adducts in livers with hemochromatosis and alcoholic liver disease (37). In NASH, the expression of $8-\mathrm{OHdG}$ in the liver has been frequently observed, and 4-HNE adducts were found to be localized in hepatocytes with a predominance in zone 3 (46). Criteria for inclusion in Group $\mathrm{N}$ excluded cases with these liver diseases associated with the development of HCC. For further analysis, it is necessary to compare the oxidative stress marker expression levels in livers of Group N patients and patients with $\mathrm{HCC}$ with such diagnosed chronic liver diseases.
The clinical data shown in Table I, as well as lower grades of hepatic inflammatory activity and lower fibrotic stages in the livers of Group N shown in Table II, are similar to results reported previously, as features of $\mathrm{HCC}$ without chronic viral infection (47-50). Significantly more patients were diagnosed with type 2 DM in Group N than in Groups B or C. Davila et al showed that the incidence of HCC was increased 2- to 3-fold in patients with DM, regardless of the presence of other major HCC risk factors, including HCV and HBV infection (10). DM is known to be associated with NASH, and the development of HCC from DM-related NASH has been reported (14). Cases diagnosed as NASH by histological examination were excluded from this study; however, one case with cirrhotic liver tissue might possibly have been 'burnt-out' NASH. Metabolic disorders, including insulin resistance, may be involved in hepatocarcinogenesis, even in livers without NASH.

In conclusion, the expression patterns of oxidative stress markers in normal livers or livers damaged by unknown etiologies were considerably different from those in livers with chronic viral hepatitis at the time of resection for HCC. 8-OHdG is reported to be important in the development of $\mathrm{HCC}$ in patients with $\mathrm{CH}-\mathrm{C}$ and $\mathrm{CH}-\mathrm{B}$, but may not be critical in patients without known liver disease predisposing to HCC. 4-HNE may possibly be associated with carcinogenesis in the latter, although these cases may have various unknown risk factors for HCC. To assess hepatocarcinogenesis resulting from oxidative stress in detail, further study with larger sample sizes is needed to determine the specific associations of markers of oxidative stress and HCC in the setting of different states of underlying hepatic disease. The number of HCC cases with cryptogenic hepatitis and in normal livers are expected to increase in the future. Thus, clarification of the mechanism involved in the occurrence of HCC in normal livers or livers damaged by unknown etiologies is critical for establishing treatments, including vitamin $\mathrm{C}$ and $\mathrm{E}$, which inhibit lipid peroxidation, and for the prevention of $\mathrm{HCC}$ in patients with DM.

\section{Acknowledgements}

This study was supported in part by Health and Labour Sciences Research Grants for Research on Hepatitis from the Ministry of Health, Labour and Welfare of Japan. 


\section{References}

1. Wong F and Choi T: Primary liver cancer. Asian experience. In: Surgery of Liver and Biliary Tract. Blumgart LH (ed). ChurchillLivingstone, London, pp1135-1151, 1988.

2. The Research Group for Population-based Cancer Resistration in Japan: Cancer incidence and incidence rates in Japan in 1995 estimates based on data from nine population-based cancer registries. Jpn J Clin Oncol 30: 318-321, 2000.

3. Tanaka $\mathrm{H}$ and Tsukuma $\mathrm{H}$ : Hepatitis $\mathrm{C}$ virus. In: Cancer Surveys: Infections and Human Cancer. Newton R, Beral V, Weiss RA and Tooze J (eds). Cold Spring Harbor Laboratory, New York, pp213-235, 1999

4. Di Bisceglie AM, Goodman ZD, Ishak KG, Hoofnagle JH, Melpolder JJ and Alter HJ: Long-term clinical and histopathological follow-up of chronic posttransfusion hepatitis. Hepatology 14: 969-974, 1991.

5. Kiyosawa K, Sodeyama T, Tanaka E, et al: Interrelationship of blood transfusion, non-A, non-B hepatitis and hepatocellular carcinoma: analysis by detection of antibody to hepatitis $\mathrm{C}$ virus. Hepatology 12: 671-675, 1990.

6. Marrero JA, Fontana RJ, Su GL, Conjeevaram HS, Emick DM and Lok AS: NAFLD may be a common underlying liver disease in patients with hepatocellular carcinoma in the United States. Hepatology 36: 1349-1354, 2002

7. Davila JA, Morgan RO, Shaib Y, McGlynn KA and El-Serag HB Hepatitis $C$ infection and the increasing incidence of hepatocellular carcinoma: a population-based study. Gastroenterology 127: $1372-1380,2004$.

8. Seeff LB and Hoofnagle JH: Epidemiology of hepatocellular carcinoma in areas of low hepatitis B and hepatitis C endemicity. Oncogene 25: 3771-3777, 2006.

9. Hatanaka K, Kudo M, Fukunaga T, et al: Clinical characteristics of NonBNonC-HCC: Comparison with HBV and HCV related HCC. Intervirology 50: 24-31, 2007.

10. Davila JA, Morgan RO, Shaib Y, McGlynn KA and El-Serag HB: Diabetes increases the risk of hepatocellular carcinoma in the United States: a population based case control study. Gut 54 533-539, 2005

11. Gerber M, Thung S and Popper H: Pathology of alcoholic liver injury. Update 1981 and problems. In: New Trends in Hepatology. Oda T and Okuda K (eds). Medical Tokyo Co. Ltd., Tokyo, pp8-12, 1986.

12. Haddow JE, Palomaki GE, McClain M and Craig W: Hereditary haemochromatosis and hepatocellular carcinoma in males: a strategy for estimating the potential for primary prevention. J Med Screen 10: 11-13, 2003.

13. Moucari R, Rautou PE, Cazals-Hatem D, et al: Hepatocellular carcinoma in Budd-Chiari syndrome: characteristics and risk factors. Gut 57: 828-835, 2008

14. Hashimoto E, Yatsuji S, Kaneda $\mathrm{H}$, et al: The characteristics and natural history of Japanese patients with nonalcoholic fatty liver disease. Hepatol Res 33: 72-76, 2005.

15. Sasaki Y: Does oxidative stress participate in the development of hepatocellular carcinoma? J Gastroenterol 41: 1135-1148, 2006.

16. Shibutani S, Takeshita M and Grollman AP: Insertion of specific bases during DNA synthesis past the oxidation-damaged base 8-oxodG. Nature 349: 431-434, 1991.

17. Hussain SP and Harris CC: Molecular epidemiology of human cancer: contribution of mutation spectra studies of tumor suppressor genes. Cancer Res 58: 4023-4037, 1998.

18. Zhang H, Xu Y, Kamendulis LM and Klaunig JE: Morphological transformation by 8-hydroxy-2'-deoxyguanosine in Syrian hamster embryo (SHE) cells. Toxicol Sci 56: 303-312, 2000.

19. Nakae D, Kobayashi Y, Akai H, et al: Involvement of 8-hydroxyguanine formation in the initiation of rat liver carcinogenesis by low dose levels of N-nitrosodiethylamine. Cancer Res 57: 1281-1287, 1997

20. Kitada T, Seki S, Iwai S, Yamada T, Sakaguchi H and Wakasa K In situ detection of oxidative DNA damage, 8-hydroxydeoxyguanosine, in chronic human liver disease. J Hepatol 35 613-618, 2001

21. Ichiba M, Maeta Y, Mukoyama T, et al: Expression of 8-hydroxy2'-deoxyguanosine in chronic liver disease and hepatocellular carcinoma. Liver Int 23: 338-345, 2003.

22. Bartsch $\mathrm{H}$ and Nair J: Oxidative stress and lipid peroxidationderived DNA-lesions in inflammation driven carcinogenesis. Cancer Detect Prev 28: 385-391, 2004.
23. Hu W, Feng Z, Eveleigh J, et al: The major lipid peroxidation product, trans-4-hydroxy-2-nonenal, preferentially forms DNA adducts at codon 249 of human p53 gene, a unique mutational hotspot in hepatocellular carcinoma. Carcinogenesis 23: 1781-1789, 2002.

24. Liu R, Buettner GR and Oberley LW: Oxygen free radicals mediate the induction of manganese superoxide dismutase gene expression by TNF-alpha. Free Radic Biol Med 28: 1197-1205, 2000.

25. Qadri I, Iwahashi M, Capasso JM, et al: Induced oxidative stress and activated expression of manganese superoxide dismutase during hepatitis $\mathrm{C}$ virus replication: role of JNK, p38 MAPK and AP-1. Biochem J 378: 919-928, 2004

26. Pugh RN, Murray-Lyon IM, Dawson JL, Pietroni MC and Williams R: Transection of the oesophagus for bleeding oesophageal varices. Br J Surg 60: 646-649, 1973.

27. Nanashima A, Sumida Y, Morino S, et al: The Japanese integrated staging score using liver damage grade for hepatocellular carcinoma in patients after hepatectomy. Eur J Surg Oncol 30: 765-770, 2004.

28. Liver Cancer Study Group of Japan (eds): General Rules for the Clinical and Pathological Study of Primary Liver Cancer. 2nd English edition. Kanehara, Tokyo, 2003.

29. Sobin L and Witteking C (eds): International Union Against Cancer. Union TMN Classification of malignant tumors. 5th edition. John Wiley \& Sons, Inc., New York, 1997.

30. Desmet VJ, Gerber M, Hoofnagle JH, Manns M and Scheuer PJ: Classification of chronic hepatitis: diagnosis, grading and staging. Hepatology 19: 1513-1520, 1994.

31. Brunt EM, Janney CG, Di Bisceglie AM, Neuschwander-Tetri BA and Bacon BR: Nonalcoholic steatohepatitis: a proposal for grading and staging the histological lesions. Am J Gastroenterol 94: 2467-2474, 1999 .

32. Deugnier YM, Loreal O, Turlin B, et al: Liver pathology in genetic hemochromatosis: a review of 135 homozygous cases and their bioclinical correlations. Gastroenterology 102: 2050-2059, 1992.

33. Chuma M, Hige S, Nakanishi M, et al: 8-Hydroxy-2'-deoxyguanosine is a risk factor for development of hepatocellular carcinoma in patients with chronic hepatitis $\mathrm{C}$ virus infection. $\mathrm{J}$ Gastroenterol Hepatol 23: 1431-1436, 2008.

34. Tanaka H, Fujita N, Sugimoto R, et al: Hepatic oxidative DNA damage is associated with increased risk for hepatocellular carcinoma in chronic hepatitis C. Br J Cancer 98: 580-586, 2008.

35. Matsumoto K, Satoh Y, Sugo H, et al: Immunohistochemical study of the relationship between 8-hydroxy-2'-deoxyguanosine levels in noncancerous region and postoperative recurrence of hepatocellular carcinoma in remnant liver. Hepatol Res 25: 435-441, 2003

36. Maki A, Kono H, Gupta M, et al: Predictive power of biomarkers of oxidative stress and inflammation in patients with hepatitis $\mathrm{C}$ virus-associated hepatocellular carcinoma. Ann Surg Oncol 14: 1182-1190, 2007.

37. Paradis V, Kollinger M, Fabre M, Holstege A, Poynard T and Bedossa P: In situ detection of lipid peroxidation by-products in chronic liver diseases. Hepatology 26: 135-142, 1997.

38. Kageyama F, Kobayashi Y, Kawasaki T, Toyokuni S, Uchida K and Nakamura H: Successful interferon therapy reverses enhanced hepatic iron accumulation and lipid peroxidation in chronic hepatitis C. Am J Gastroenterol 95: 1041-1050, 2000.

39. Coleman JD, Prabhu KS, Thompson JT, et al: The oxidative stress mediator 4-hydroxynonenal is an intracellular agonist of the nuclear receptor peroxisome proliferator-activated receptorbeta/delta (PPARbeta/delta). Free Radic Biol Med 42: 1155-1164, 2007.

40. Boya P, de la Pena A, Beloqui O, et al: Antioxidant status and glutathione metabolism in peripheral blood mononuclear cells from patients with chronic hepatitis C. J Hepatol 31: 808-814, 1999.

41. Kawaguchi T, Suzuki K, Matsuda Y, et al: Serum-manganesesuperoxide dismutase: normal values and increased levels in patients with acute myocardial infarction and several malignant diseases determined by an enzyme-linked immunosorbent assay using a monoclonal antibody. J Immunol Methods 127: 249-254 1990.

42. Aida Y, Maeyama S, Takakuwa T, et al: Immunohistochemical expression of manganese superoxide dismutase in hepatocellular carcinoma, using a specific monoclonal antibody. J Gastroenterol 29: 443-449, 1994. 
43. Clemente C, Elba S, Buongiorno G, et al: Manganese superoxide dismutase activity and incidence of hepatocellular carcinoma in patients with Child-Pugh class A liver cirrhosis: a 7-year follow-up study. Liver Int 27: 791-797, 2007.

44. Sutton A, Nahon P, Pessayre D, et al: Genetic polymorphisms in antioxidant enzymes modulate hepatic iron accumulation and hepatocellular carcinoma development in patients with alcoholinduced cirrhosis. Cancer Res 66: 2844-2852, 2006.

45. Ezzikouri S, El Feydi AE, Chafik A, et al: Genetic polymorphism in the manganese superoxide dismutase gene is associated with an increased risk for hepatocellular carcinoma in $\mathrm{HCV}$-infected Moroccan patients. Mutat Res 649: 1-6, 2008.

46. Seki S, Kitada T, Yamada T, Sakaguchi H, Nakatani K and Wakasa K: In situ detection of lipid peroxidation and oxidative DNA damage in non-alcoholic fatty liver diseases. J Hepatol 37: 56-62, 2002
47. Toyoda H, Kumada T, Kiriyama S, et al: Characteristics and prognosis of patients in Japan with viral marker-negative hepatocellular carcinoma. J Gastroenterol Hepatol 23: 459-466, 2008.

48. Higashi Y, Tada S, Miyase S, et al: Correlation of clinical characteristics with detection of hepatitis $B$ virus $X$ gene in liver tissue in $\mathrm{HBsAg}$-negative, and $\mathrm{HCV}$-negative hepatocellular carcinoma patients. Liver 22: 374-379, 2002.

49. Yokoi Y, Suzuki S, Baba S, Inaba K, Konno H and Nakamura S: Clinicopathological features of hepatocellular carcinomas (HCCs) arising in patients without chronic viral infection or alcohol abuse: a retrospective study of patients undergoing hepatic resection. J Gastroenterol 40: 274-282, 2005.

50. Watabe H, Shiratori Y, Tateishi R, et al: Clinical features of patients with HCC who are negative for both HBV and HCV markers. Hepatogastroenterology 50: 2157-2160, 2003. 